\title{
Attention deficit-hyperactivity disorder in patients in rehabilitation of drug addiction
}

\author{
Transtorno do déficit de atenção e hiperatividade em pacientes em \\ reabilitação de drogadição
}

Marilisa M. Guerreiro'

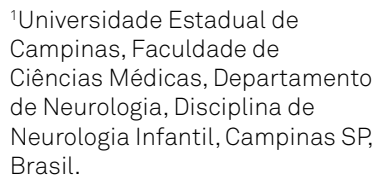

'Universidade Estadual de Campinas, Faculdade de Ciências Médicas, Departamento de Neurologia, Disciplina de Neurologia Infantil, Campinas SP, Brasil.

\section{Correspondence:}

Marilisa Mantovani Guerreiro;

Departamento de Neurologia, FCM

/ UNICAMP; Rua Tessália Vieira de

Camargo, 126;13083-887 Campinas

SP, Brasil.

E-mail:mmg@fcm.unicamp.br

Conflict of interest:

There is no conflict of interest to declare.

Received 16 November 2016; Accepted 23 November 2016.

\section{(c) BY}

A ttention deficit-hyperactivity disorder (ADHD), the most prevalent neurobehavioral disorder in children, is associated with adverse long-term functional outcomes ${ }^{1}$. Population surveys suggest that ADHD occurs in most cultures in about $5 \%$ of children and about $2.5 \%$ of adults ${ }^{2}$. Coexisting conditions and problems, such as learning disabilities, anxiety, depression, oppositional behaviors and conduct disturbance, must be considered in the evaluation and management of $\mathrm{ADHD}^{1,2}$. Behavioral comorbidities have been increasingly recognized and they may lead to drug use and dependence. In this issue, Camargo and colleagues ${ }^{3}$ report the investigation of the relationship between ADHD and drug dependence in 80 adult patients in therapeutic communities. This study reached three important conclusions .

The first significant finding was that $61.25 \%$ of the addicted patients had ADHD. This prevalence is much higher than the figures shown above for the general population. Other authors $^{4,5}$ found similar results showing that ADHD patients are at higher risk to develop drug addiction and cocaine dependence. The treatment of ADHD seems to decrease the risk for substance use disorders ${ }^{4}$.

The second significant finding in the study of Camargo and colleagues ${ }^{3}$ was that ADHD patients had an earlier age at first use of cocaine. ADHD is appointed as a risk factor for early onset use of illicit substances ${ }^{6,7}$. The risk of dependence on alcohol or other substances is significantly higher in adolescents with $\mathrm{ADHD}$ than is in healthy adolescents ${ }^{8}$. Concerning the clinical characteristics of $\mathrm{ADHD}$ individuals, the impulsive subtype patients usually have a greater tendency to use substances and develop dependence ${ }^{9}$.

The third significant finding in the study of Camargo and colleagues ${ }^{3}$ was that more severe use of cocaine correlated with earlier contact with cannabis. A community-based study ${ }^{10}$ aimed to assess the link between ADHD and substance use 18 years later following 1103 French youths from 1991 to 2009. The results showed that early cannabis exposure plays a central role in later substance use. The figures are robust enough to support its important conclusion, reinforcing the findings of Camargo and colleagues ${ }^{3}$.

Concerns have been raised about increased diagnosis of ADHD. The prevalence of this condition has indeed increased in the United States suggesting overdiagnosis or overreporting ${ }^{10}$. Marketing for physicians and the general public has been blamed for those who do not believe in the high prevalence of ADHD. However, there are also indications of underdiagnosis ${ }^{10}$.

All three significant findings in the study of Camargo and colleagues ${ }^{3}$ point to the connection between ADHD and substance use. To deny this reality is not a wise attitude; instead, doctors, parents, caregivers and social workers must be aware of this reality in order to take effective and preventive measures in an attempt to reduce the individual harm and social burden of illicit drug use. 
1. Feldman HM, Reiff MI. Attention deficit-hyperactivity disorder in children and adolescents. N Engl J Med. 2014;370(9):838-46. doi:10.1056/NEJMcp1307215

2. American Psychiatric Association. Diagnostic and statistical manual of mental disorders. 5th ed. Arlington, VA: American Psychiatric Association; 2013.

3. Camargo CHF, Dornelles TF, Barszcz K, Martins EA. Attention deficit hyperactivity disorder and drug addiction rehabilitation patients. Arq Neuropsiquiatr. 2016;74(12):1003-7. doi: 10.1590/0004-282X20160163

4. Wilens TE, Biederman J. Alcohol, drugs, and attention-deficit/hyperactivity disorder: a model for the study of addictions in youth. J Psychopharmacol. 2006;20(4):580-8. doi:10.1177/0269881105058776

5. Capusan AJ, Bendtsen P, Marteinsdottir I, Larsson H. Comorbidity of adult ADHD and its subtypes with substance use disorder in a large population-based epidemiological study. J Atten Disord. 2016;pii:1087054715626511. doi:10.1177/1087054715626511
6. Carroll KM, Rounsaville BJ. History and significance of childhood attention deficit disorder in treatment-seeking cocaine abusers. Compr Psychiatry. 1993;34(2):75-82. doi:10.1016/0010-440X(93)90050-E

7. Dunne EM, Hearn LE, Rose JJ, Latimer WW. ADHD as a risk factor for early onset and heightened adult problem severity of illicit substance use: an accelerated gateway model. Addict Behav. 2014;39(12):1755-8. doi:10.1016/j.addbeh.2014.07.009

8. Tapert SF, Baratta MV, Abrantes AM, Brown SA. Attention dysfunction predicts substance involvement in community youths. J Am Acad Child Adolesc Psychiatry. 2002;41(6):680-6. doi:10.1097/00004583-200206000-00007

9. De Alwis D, Lynskey MT, Reiersen AM, Agrawal A. Attention-deficit/hyperactivity disorder subtypes and substance use and use disorders in NESARC. Addict Behav. 2014:39(8):1278-85. doi:10.1016/j.addbeh.2014.04.003

10. Galéra C, Pingault JB, Fombonne E, Michel G, Lagarde E, Bouvard MP et al. Attention problems in childhood and adult substance use. J Pediatr. 2013;163(6):1677-83. doi:10.1016/j.jpeds.2013.07.008 